\title{
Clinical characteristics and treatments of large cell lung carcinoma: a retrospective study using SEER data
}

\author{
Qidong Tai, Lei Zhang, Xuefei Hu \\ Thoracic Department of Shanghai Pulmonary Hospital, Tongji University School of Medicine, Shanghai 200433, China \\ Contributions: (I) Conception and design: X Hu, L Zhang; (II) Administrative support: None; (III) Provision of study materials or patients: None; \\ (IV) Collection and assembly of data: Q Tai; (V) Data analysis and interpretation: Q Tai; (VI) Manuscript writing: All authors; (VII) Final approval of \\ manuscript: All authors. \\ Correspondence to: Lei Zhang, MD; Xuefei Hu, MD. Thoracic Department of Shanghai Pulmonary Hospital, Tongji University School of Medicine, \\ Shanghai 200433, China. Email: 13816121971@163.com; huxuefei_12345@163.com.
}

Background: Large cell lung carcinoma (LCLC) is a rare malignancy with poor outcome, and little is known about its clinical characteristics and treatments.

Methods: The clinical information of LCLC patients was collected from the Surveillance, Epidemiology, and End Results (SEER) database between 2004 and 2015. The Kaplan-Meier method was used to determine the overall survival (OS) and lung cancer-specific survival (LCSS). Univariate and multivariate analyses were further performed to investigate the independent prognostic factors of OS. A final nomogram was built using the Cox proportional hazards model.

Results: In total, 4,099 patients diagnosed with LCLC were included. $70.2 \%$ of patients were older than 60 , and more male patients were found. Besides, $60.2 \%$ of lesions were found in the upper lobe. Moreover, most patients showed poor differentiation and presented with stage III or IV. Multivariate Cox analysis revealed age, gender, marital status, laterality, tumor size, stage, chemotherapy and surgery were independent prognostic factors of LCLC. The prognosis after surgery combined with chemotherapy was better than that after surgery alone $(\mathrm{P}=0.041, \mathrm{HR}=0.875,95 \% \mathrm{CI}$ : 0.771-0.993). The nomogram had good discrimination with a concordance index of 0.757 .

Conclusions: LCLC is more common in the elderly and males. Most of lesions are located in the upper lobe and are diagnosed at stage III/IV with poor differentiation. Age, gender, marital status, laterality, tumor size, stage, chemotherapy and surgery were associated with OS. Surgery combined with chemotherapy may achieve a better prognosis and the nomogram accurately predicted the 1-, 3-, and 5-year OS.

Keywords: Large cell lung carcinoma (LCLC); Surveillance, Epidemiology, and End Results (SEER); treatment; prognosis

Submitted Aug 11, 2019. Accepted for publication Dec 26, 2019.

doi: $10.21037 /$ tcr.2020.01.40

View this article at: http://dx.doi.org/10.21037/tcr.2020.01.40

\section{Introduction}

Lung cancer is the most common malignant tumor in the world and has the highest fatality rate (1). It consists of non-small cell lung cancer (NSCLC) and small cell lung cancer (SCLC). Histologically, NSCLC can be further classified as adenocarcinoma, squamous cell carcinoma and large cell carcinoma with or without neuroendocrine features. In NSCLC, according to cohort demographics and classification scheme, large cell lung cancer (LCLC) only accounts for $9 \%$ of all cases and often has poor differentiation and prognosis (2-5). Based on the WHO lung cancer classification (6), LCLC is defined as an undifferentiated non-small cell 
carcinoma, because it lacks the cellular and structural characteristics related to the adenocarcinoma or squamous cell carcinoma. The diagnosis of LCLC mainly depends on post-operative pathological examination rather than biopsy and cytological examination (7). There is evidence showing that LCLC is frequently found in males and smokers and often presents as a large mass with central necrosis (8-10). Furthermore, LCLC is more commonly seen in the elderly $(>60)$, and its clinical symptoms and signs correlate with the location and the extent of invasion.

Due to its low incidence and a lack of relevant clinical data, less is known about its clinical and biological characteristics. In this retrospective study, the clinical information of patients with LCLC registered in the Surveillance, Epidemiology and End Results (SEER) database was extracted and analyzed, aiming to better understand its clinical behaviors and factors affecting the survival of patients.

\section{Methods}

\section{Data extraction}

The SEER database includes the information on cancer incidence and survival from 18 cancer registries, covering $26 \%$ of the population. Data for patients diagnosed with LCLC during 2004-2015 were extracted using the SEER*Stat software version 8.3.5. The study cohort contained patients according to the International Classification of Disease for Oncology, third edition (ICD-O-3) histology code 8012/3 (Large cell carcinoma, NOS), 8013/3 (Large cell neuroendocrine carcinoma), and $8014 / 3$ (Large cell carcinoma with rhabdoid phenotype).Based on the 2004 WHO classification, large cell neuroendocrine carcinoma belongs to the family of large cell carcinoma. Therefore, such patients were also comprised in the cohort. The exclusion criteria were as follows: (I) patients had more than one primary tumors; (II) patients had no data on the survival; (III) the diagnosis was not pathologically confirmed; (IV) patients without clinicopathological information, including age, gender, race, marital status, primary site, laterality, grade, size, AJCC stage, chemotherapy and surgery. The clinical staging was determined according to the eighth TNM edition through the $\mathrm{R}$ version 3.4.3 software.

The outcomes included overall survival (OS) and lung cancer-specific survival (LCSS). The analysis cut-off date was 31 December 2015. OS was defined as the time from diagnosis to death from any cause or until the most recent follow-up. And the LCSS was defined as the time from diagnosis to either death caused by disease or last follow-up. In the SEER database, patients who survived for less than 1 month were coded with a survival time of zero. Therefore, a survival of 0.5 months was assigned to these patients following the standard epidemiological convention.

\section{Statistical analysis}

Categorical variables were analyzed with the Chi-square test. To adjust for the bias between surgical patients with or without chemotherapy, the propensity-matched (PSM) analysis was adopted. The PSM module was based upon age, gender, race, marital status, primary site, laterality, grade, size, and stage. Cumulative survival curves were determined using the Kaplan-Meier method and compared using the log-rank test. To perform univariate and multivariate analyses, Cox proportional hazards model was employed. Only variables that were significantly associated with the survival in univariate Cox analysis were included in the multivariate Cox analysis. Hazard ratio (HR) and 95\% confidence interval (CI) were presented. And the nomogram was delineated based on the results of multivariate Cox analysis by using $\mathrm{R}$ version 3.4.3 software. The prediction error was estimated with 1000 bootstrap samples. A value of two-sided $\mathrm{P}<0.05$ was considered statistically significant. Statistical analysis was performed with the software $\mathrm{R}$ version 3.4.3 and SPSS 25.0 (SPSS, Chicago, IL). GraphPad Prism 5.0 (GraphPad Software, San Diego, CA) was used to delineate the survival curve.

\section{Results}

\section{Clinical characteristics}

As shown in Table 1, a total of 4,008 patients were diagnosed with LCLC between 2004 and 2015, and $70.2 \%$ of patients were older than 60 years. Slightly more than half of the patients were male $(57.6 \%)$. In addition, the majority $(53.9 \%)$ was married and $58.1 \%$ of tumors located in the right lung ( $41.4 \%$ in the left lung). Interestingly, the upper lobe was the most common site of lesions $(60.2 \%)$, followed by the lower lobe $(24.9 \%)$. And $97.8 \%$ of tumors showed poor differentiation or undifferentiation. Correspondingly, stage III/IV tumors accounted for $57.4 \%$, while $20.1 \%$ and $12.5 \%$ of tumors were diagnosed at stage I and II, 
Table 1 Characteristics of 4,008 patients with LCLC

\begin{tabular}{|c|c|}
\hline Characteristics & Number of cases (\%) \\
\hline Total & 4,008 \\
\hline \multicolumn{2}{|l|}{ Age } \\
\hline$\leq 60$ & 1,196 (29.8) \\
\hline$>60$ & $2,812(70.2)$ \\
\hline \multicolumn{2}{|l|}{ Gender } \\
\hline Female & $1,699(42.4)$ \\
\hline Male & $2,309(57.6)$ \\
\hline \multicolumn{2}{|l|}{ Race } \\
\hline White & $3,273(81.7)$ \\
\hline Black & $538(13.4)$ \\
\hline $\begin{array}{l}\text { Other (American Indian/AK Native, } \\
\text { Asian/Pacific Islander) }\end{array}$ & $197(4.9)$ \\
\hline \multicolumn{2}{|l|}{ Marital Status } \\
\hline Married & $2,161(53.9)$ \\
\hline Single & $566(14.1)$ \\
\hline Other (Separated/Divorced/Widowed) & $1281(32)$ \\
\hline \multicolumn{2}{|l|}{ Primary site } \\
\hline Main bronchus & $159(4)$ \\
\hline Upper lobe, lung & $2,411(60.2)$ \\
\hline Middle lobe, lung & $188(4.7)$ \\
\hline Lower lobe, lung & $998(24.9)$ \\
\hline Overlapping lesion & $56(1.4)$ \\
\hline Lung, NOS & $196(4.9)$ \\
\hline \multicolumn{2}{|l|}{ Laterality } \\
\hline Left & $1,658(41.4)$ \\
\hline Right & $2,328(58.1)$ \\
\hline Bilateral & $22(0.5)$ \\
\hline \multicolumn{2}{|l|}{ Grade } \\
\hline Well/Moderate & $89(2.2)$ \\
\hline Poor/Undifferentiated & $3,919(97.8)$ \\
\hline \multicolumn{2}{|l|}{ Tumor size $(\mathrm{cm})$} \\
\hline$\leq 3$ & $1,327(33.1)$ \\
\hline $3-5$ & $1,174(29.3)$ \\
\hline $5-7$ & $718(17.9)$ \\
\hline$\geq 7$ & 789 (19.7) \\
\hline
\end{tabular}

Table 1 (continued)
Table 1 (continued)

\begin{tabular}{lc}
\hline Characteristics & Number of cases (\%) \\
\hline Stage & $807(20.1)$ \\
II & $501(12.5)$ \\
III & $966(24.1)$ \\
IV & $1,734(43.3)$ \\
Chemotherapy & \\
No/Unknown & $2,181(54.4)$ \\
Yes & $1,827(45.6)$ \\
Surgery & \\
No/Unknown & $2,364(59)$ \\
Yes & $1,644(41)$ \\
\hline
\end{tabular}

respectively. Moreover, the size of most tumors (62.4\%) was less than $5 \mathrm{~cm}$.

\section{Treatments}

Table 2 shows the relevant treatments of LCLC. Only $26.1 \%$ of patients received surgery alone, while $15.0 \%$ of cases accepted surgery combined with chemotherapy. There were meaningful differences in the age, marital status, tumor size and stage between surgical patients with or without chemotherapy $(\mathrm{P}<0.05$ for all). Neither distribution of gender, race, primary site, laterality nor grade differed significantly between objects who selected surgery or surgery plus chemotherapy. Furthermore, the results of the correlational analysis presented that with the improvement of size and stage, patients were more inclined to choose comprehensive treatment.

\section{Survival}

The median OS and LCSS were 35 months (95\% CI: 30.61-39.40) and 55 months (95\% CI: 43.29-66.71), respectively. Figure 1 show the OS and LCSS curves. Meanwhile, the overall 1-, 3- and 5-year survival rates were $45.6 \%, 24.8 \%$, and $19.0 \%$. Correspondingly, the $1-$, 3 -, and 5 -year of LCSS were $49.1 \%, 28.8 \%$ and $24.1 \%$, respectively. In addition, the median survival time was 34 months (range: 28.59-39.41 months) in patients 
Table 2 Surgically treated patients with or without chemotherapy

\begin{tabular}{|c|c|c|c|}
\hline \multirow{2}{*}{ Characteristics } & \multicolumn{2}{|c|}{ Chemotherapy } & \multirow{2}{*}{$P$ value } \\
\hline & No/unknown $(n=1,045)$ & Yes $(n=599)$ & \\
\hline Age & & & $<0.01$ \\
\hline$>60$ & $795(76.1)$ & $320(53.4)$ & \\
\hline Gender & & & 0.744 \\
\hline Male & $567(54.3)$ & $330(55.1)$ & \\
\hline Race & & & 0.474 \\
\hline White & $886(84.8)$ & $506(84.5)$ & \\
\hline Black & $101(9.7)$ & $66(11)$ & \\
\hline Other (American Indian/AK Native, Asian/Pacific Islander) & $58(5.6)$ & $27(4.5)$ & \\
\hline Single & $124(11.9)$ & $73(12.2)$ & \\
\hline Other (separated/divorced/widowed) & $339(32.4)$ & $154(25.7)$ & \\
\hline Primary site & & & 0.348 \\
\hline Main bronchus & $9(0.9)$ & $5(0.8)$ & \\
\hline Upper lobe, lung & $667(63.8)$ & $400(66.8)$ & \\
\hline Middle lobe, lung & $56(5.4)$ & $21(3.5)$ & \\
\hline Lower lobe, lung & $281(26.9)$ & $150(25)$ & \\
\hline Overlapping lesion & $15(1.4)$ & $14(2.3)$ & \\
\hline Lung, NOS & $17(1.6)$ & $9(1.5)$ & \\
\hline Poor + undifferentiated & $1,008(96.5)$ & $582(97.2)$ & \\
\hline Tumor size $(\mathrm{cm})$ & & & $<0.01$ \\
\hline$\leq 3$ & $573(54.8)$ & $201(33.6)$ & \\
\hline $3-5$ & $282(27)$ & $216(36.1)$ & \\
\hline $5-7$ & $112(10.7)$ & 95 (15.9) & \\
\hline$\geq 7$ & 78 (7.5) & $87(14.5)$ & \\
\hline Stage & & & $<0.01$ \\
\hline I & $594(56.8)$ & $110(18.4)$ & \\
\hline ॥ & $211(20.2)$ & $184(30.7)$ & \\
\hline III & $153(14.6)$ & $225(37.6)$ & \\
\hline IV & $87(8.3)$ & $80(13.4)$ & \\
\hline
\end{tabular}



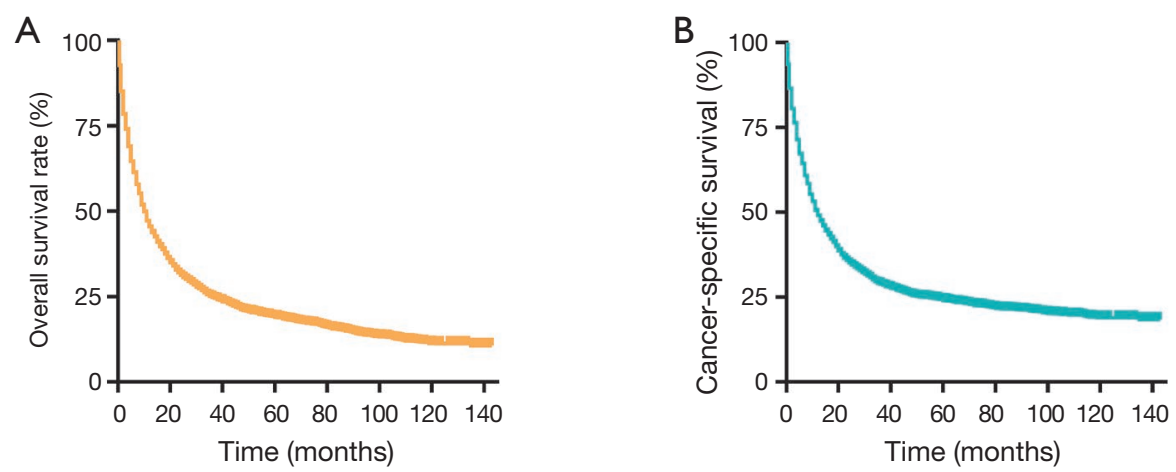

Figure 1 Kaplan Meier curve of (A) overall survival and (B) cancer-specific survival.
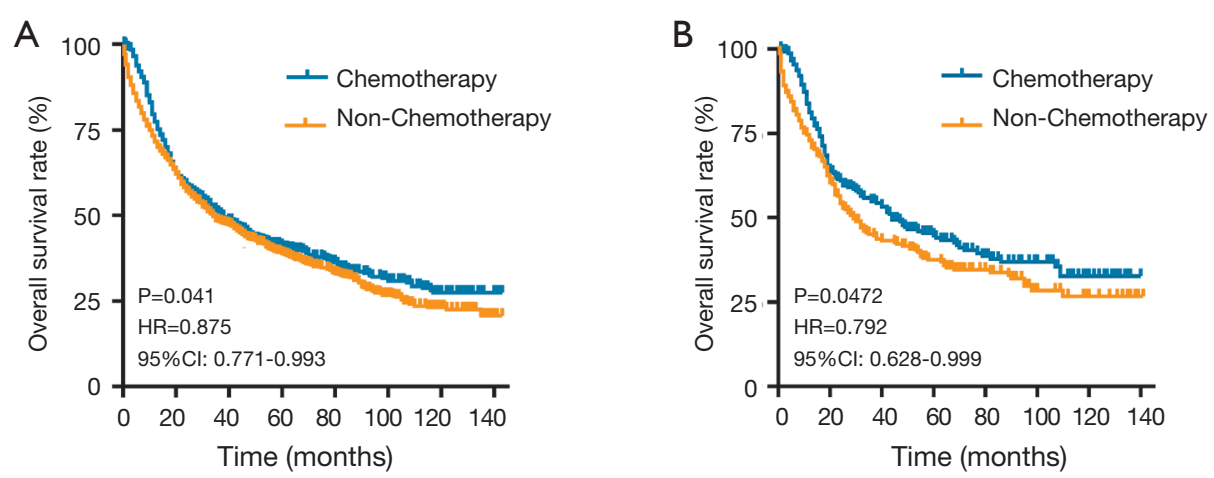

Figure 2 Kaplan-Meier curve of overall survival in surgically treated patients with/without chemotherapy before (A) and after (B) propensity score matching.

undergoing surgery alone and 38 months (range: $31.04-$ 44.99 months) in those receiving surgery plus chemotherapy (Figure 2A). Moreover, in patients with surgery alone and those with surgery combined with chemotherapy, the 1-year survival rate was $71.7 \%$ and $77.5 \%$; the 3 -year survival rate was 48.3 and $50.7 \%$; and the 5 -year survival rate was $38.8 \%$ and $41.0 \%$, separately. As shown in Figure 2B, the OS in patients receiving surgery with chemotherapy was better than in patients undergoing surgery alone $(\mathrm{P}=0.041$, HR $=0.875$, 95\% CI: 0.771-0.993).

Furthermore, the PSM analysis was done in surgical patients with or without chemotherapy based on the age, gender, race, marital status, primary site, laterality, grade, tumor size, and stage. In the analysis, 244 patients received chemotherapy and 244 subjects had no chemotherapy $(1: 1)$. There were no significant differences in the clinical characteristics between them (Table S1). OS curves and Logrank analysis indicated that patients receiving chemotherapy enhanced the survival $(\mathrm{P}=0.047, \mathrm{HR}=0.7924,95 \%$ CI: 0.628-0.999).

Variables potentially influencing OS were further investigated using the univariate Cox proportional hazards analysis. Table 3 displays the potential factors $(\mathrm{P}<0.01)$ associated with the prognosis except for the race $(\mathrm{P}=0.18)$. Further multivariate Cox analysis was performed to identify the independent prognostic elements. Results showed age $(\mathrm{P}<0.01)$, gender $(\mathrm{P}=0.01)$, marital status $(\mathrm{P}=0.004)$, laterality $(\mathrm{P}=0.015)$, tumor size $(\mathrm{P}<0.01)$, stage $(\mathrm{P}<0.01)$, chemotherapy $(\mathrm{P}<0.01)$ and surgery $(\mathrm{P}<0.01)$ were able to predict the survival of LCLC patients. The pathological grade correlated with the stage, thus it could exclude. Moreover, a nomogram (Figure 3) was-plotted based on the risk factors identified by the multivariate analysis for predicting 1-, 3-, and 5-year OS. And according to the internal bootstrap resampling validation, the calibration plot (Figure 4) was illustrated. The C-index for prediction 
Table 3 Univariate and multivariate Cox proportional hazard analyses of clinical characteristics for overall survival rate of LCLC patients

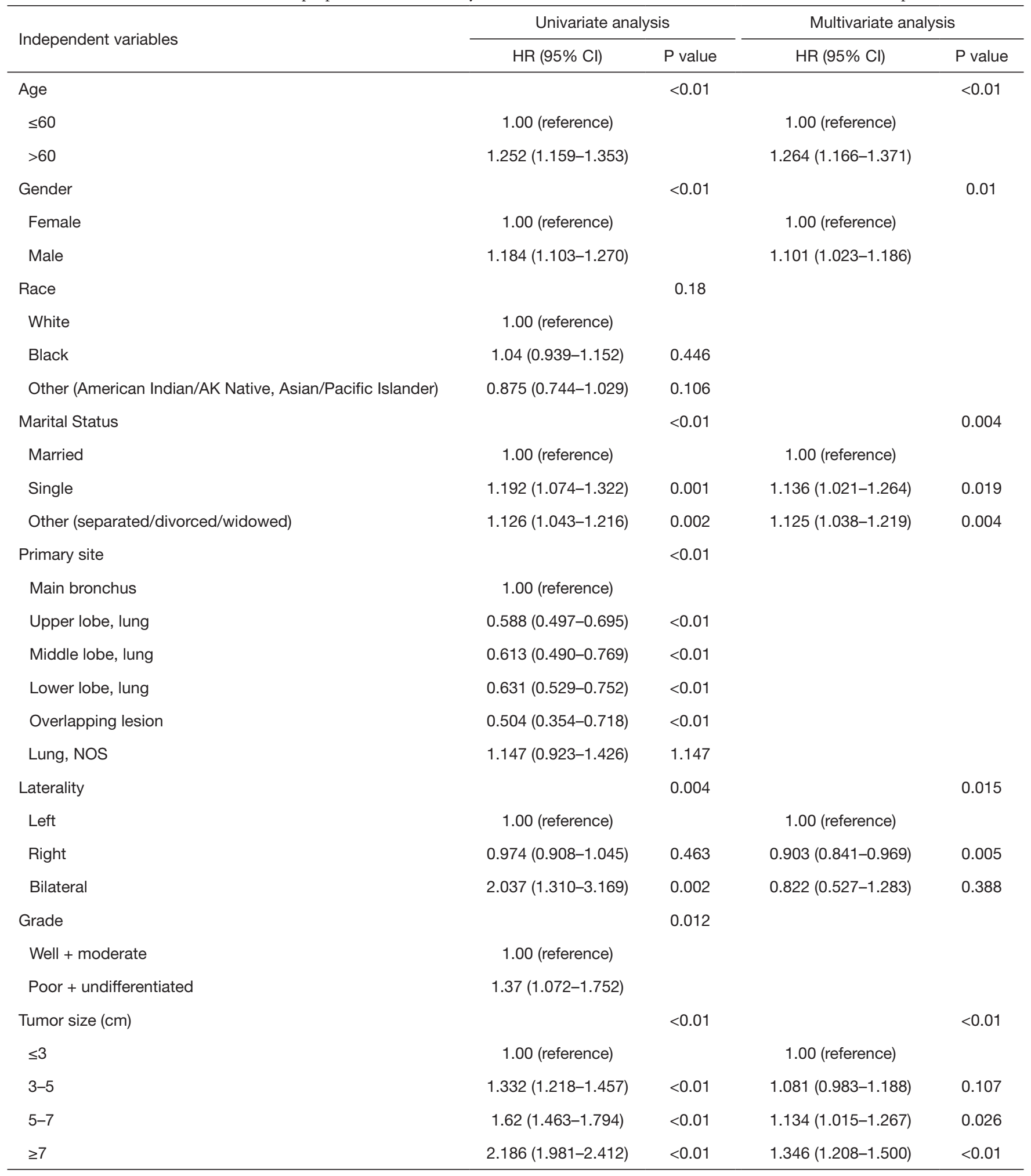

Table 3 (continued) 
Table 3 (continued)

\begin{tabular}{|c|c|c|c|c|}
\hline Independent variables & \multicolumn{2}{|c|}{ Univariate analysis } & \multicolumn{2}{|c|}{ Multivariate analysis } \\
\hline Stage & & $<0.01$ & & $<0.01$ \\
\hline I & 1.00 (reference) & & 1.00 (reference) & \\
\hline II & $1.277(1.110-1.469)$ & 0.001 & $1.386(1.192-1.611)$ & $<0.01$ \\
\hline IV & $4.831(4.348-5.367)$ & $<0.01$ & $3.454(3.018-3.953)$ & $<0.01$ \\
\hline Chemotherapy & & $<0.01$ & & $<0.01$ \\
\hline No/unknown & 1.00 (reference) & & 1.00 (reference) & \\
\hline Yes & $0.852(0.794-0.913)$ & & $0.504(0.467-0.543)$ & \\
\hline Yes & $0.282(0.261-0.305)$ & & $0.411(0.373-0.453)$ & \\
\hline
\end{tabular}

of OS was 0.757 (95\% CI: $0.749-0.765)$, which indicated a sufficient level of discrimination.

\section{Discussion}

According to the 2004 lung cancer classification (11), LCLC is a poorly differentiated tumor and accounts for about $10 \%$ of NSCLC. However, with the emergence of 2015 lung cancer classification (6), basaloid carcinoma is classified as squamous cell carcinoma, the large cell neuroendocrine carcinoma and compound large cell neuroendocrine carcinoma are classified as neuroendocrine tumors, the lymphoepithelioma-like carcinoma is categorized as other or unclassified cancer, finally, the clear cell carcinoma and LCLC with rhabdoid phenotype are not comprised. Thus, the incidence of LCLC is likely to be lower than $10 \%$, based on the new classification (9).

In our series, LCLC was more common in males and in the elderly at the time of diagnosis. In addition, lesions predominated on upper lobe, which was consistent with previous findings (12-14). Cao et al. also reported that large cell neuroendocrine carcinoma frequently observed in men and old people (15). Cao et al. (15) and Oshiro et al. (16) held that most of large cell neuroendocrine carcinoma was pathologically high-grade. In our study, $97.8 \%$ of patients showed poor differentiation at the time of diagnosis. Previous researches appeared that LCLC formed a large mass $(13,17)$. During our research, nearly half of the neoplasms was smaller than $5 \mathrm{~cm}$ in diameter.

Early diagnosis and early treatment are crucial for the survival of LCLC patients because of the poor prognosis. A prospective study on large cell neuroendocrine carcinoma showed that postoperative chemotherapy could achieve a better prognosis as compared to surgery alone (18). In addition, Kujtan et al. found that the survival time of patients with stage IA large cell neuroendocrine carcinoma who received surgery combined with chemotherapy was significantly longer than in those receiving surgery alone (19). Hanagiri et al. presented that the 5-year survival rate in patients receiving surgery for large cell carcinoma was $61.5 \%$ (13). However, the 5 -year survival rate was only $38.8 \%$ in our study. This might be ascribed to the small sample size (57 patients). Moreover, our results showed the 5 -year survival rate of patients receiving surgery combined with chemotherapy was $41 \%$, which was better than that of patients receiving surgery alone. Some studies had also recommended a combination of surgery and chemotherapy for the treatment of LCLC, and post-operative cisplatin/ pemetrexed may achieve a better prognosis than postoperative cisplatin/gemcitabine (10.4 vs. 6.7 months, respectively) (20).

There were also several limitations in our study. First, we carried out the research according to the 2004 lung cancer classification, which is different from the 2015 lung 


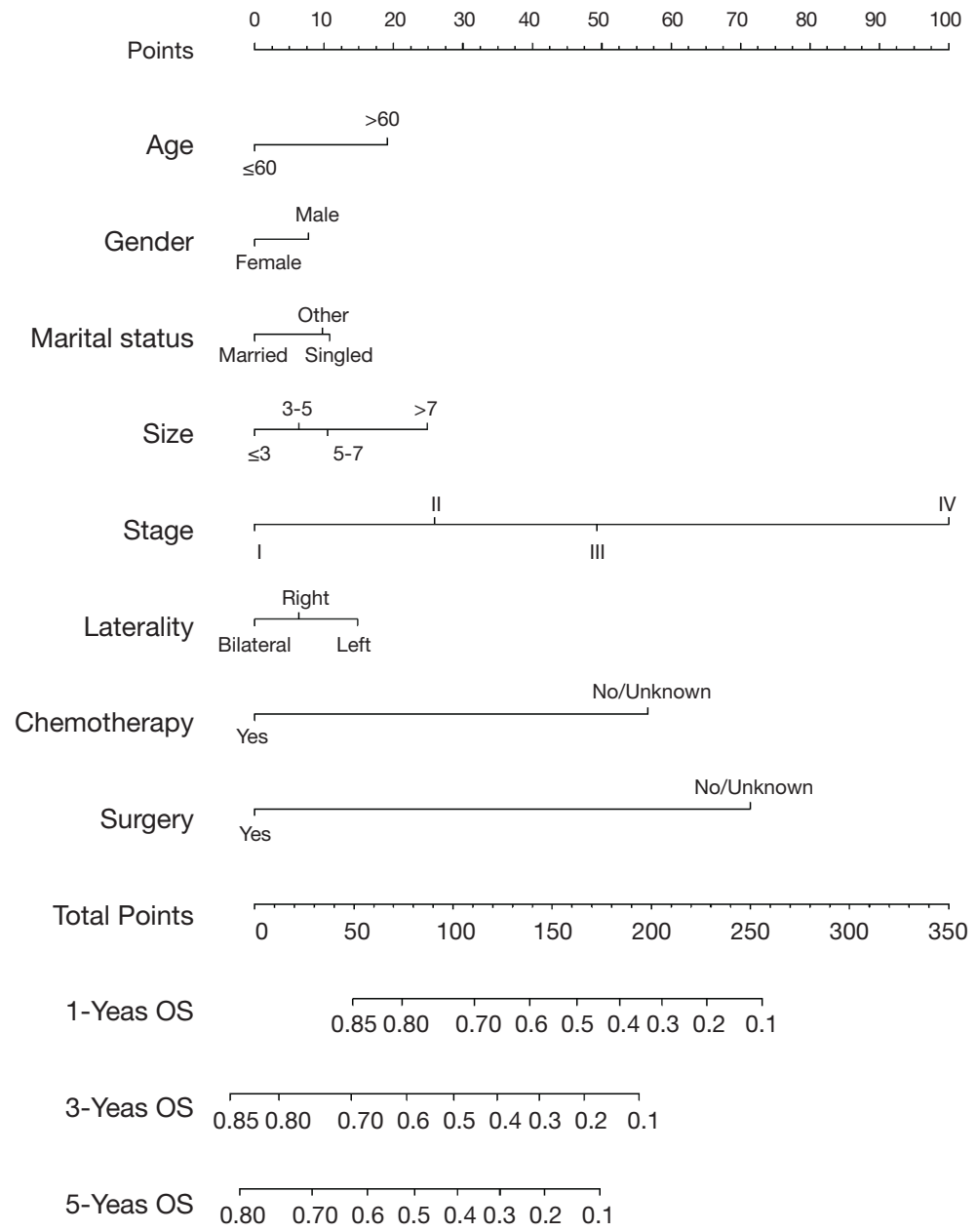

Figure 3 Nomogram to predict 1-, 3-, 5-year overall survival of patients with large cell lung cancer.
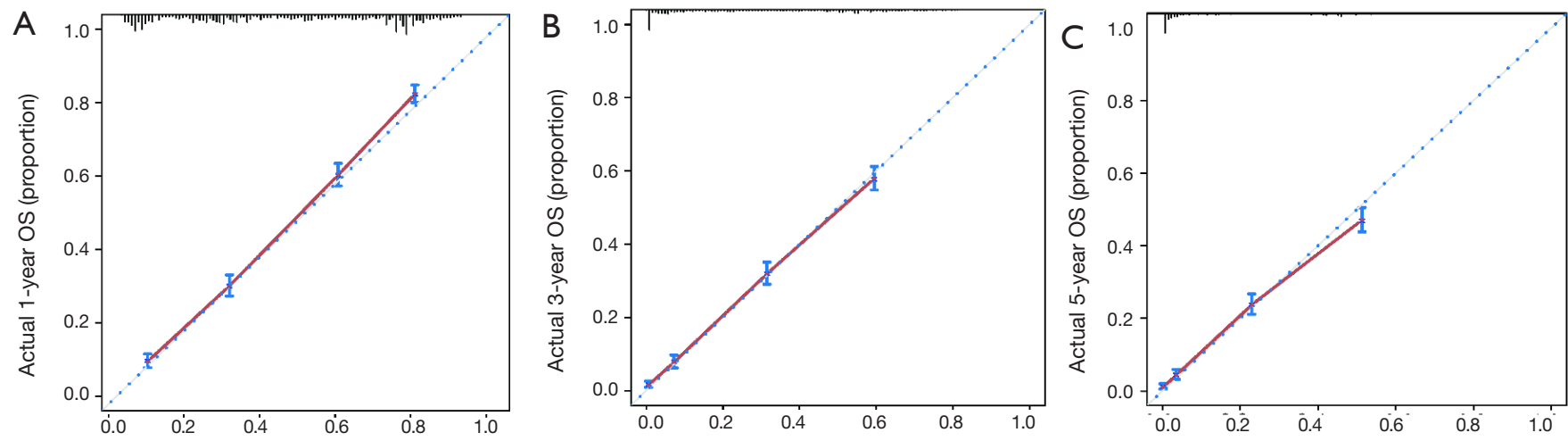

Figure 4 Calibration plots of the nomogram prediction of (A) 1-, (B) 3-, (C) 5-year overall survival of large cell lung cancer patients. 
cancer classification. Second, patients were divided into two groups according to whether they received chemotherapy or not, but the specific regimens for chemotherapy were unknown. At last, for patients diagnosed with LCLC, more prospective clinical studies are needed to elucidate the prognostic factors and further investigate the efficacy of available treatments.

In conclusion, LCLC is more common in the elderly $(>60$ years) and mainly located in the upper lobe. The majority of tumors are diagnosed at stage III/IV. Surgery combined with chemotherapy is beneficial for the prognosis of LCLC patients.

\section{Acknowledgments}

Funding: Supported by Medical guidance project of Shanghai Committee on Science and Technology (No.134119a3400) and Rising Frontiers projects of ShenKang centre (SHDC12016106).

\section{Footnote}

Conflicts of Interest: All authors have completed the ICMJE uniform disclosure form (available at http://dx.doi. org/10.21037/tcr.2020.01.40). The authors have no conflicts of interest to declare.

Ethical Statement: The authors are accountable for all aspects of the work in ensuring that questions related to the accuracy or integrity of any part of the work are appropriately investigated and resolved. The study was conducted in accordance with the Declaration of Helsinki (as revised in 2013). Institutional ethical approval and informed consent were waived.

Open Access Statement: This is an Open Access article distributed in accordance with the Creative Commons Attribution-NonCommercial-NoDerivs 4.0 International License (CC BY-NC-ND 4.0), which permits the noncommercial replication and distribution of the article with the strict proviso that no changes or edits are made and the original work is properly cited (including links to both the formal publication through the relevant DOI and the license). See: https://creativecommons.org/licenses/by-nc-nd/4.0/.

\section{References}

1. Siegel RL, Miller KD, Jemal A. Cancer statistics, 2016.
CA Cancer J Clin 2016;66:7-30.

2. Kupeli M, Koseoglu RD. Large Cell Carcinoma with Adenocarcinoma in Lung. J Coll Physicians Surg Pak 2018;28:240-2.

3. Hou LK, Zhang LP, Zhang W, et al. Clinicopathologic features and genetic profile of the redefined large cell lung carcinoma. Zhonghua Bing Li Xue Za Zhi 2017;46:298-302.

4. Rekhtman N, Tafe LJ, Chaft JE, et al. Distinct profile of driver mutations and clinical features in immunomarkerdefined subsets of pulmonary large-cell carcinoma. Mod Pathol 2013;26:511-22.

5. Chan AW, Chau SL, Tong JH, et al.The Landscape of Actionable Molecular Alterations in ImmunomarkerDefined Large-Cell Carcinoma of the Lung. J Thorac Oncol 2019;14:1213-22.

6. Travis WD, Brambilla E, Nicholson AG, et al. The 2015 World Health Organization Classification of Lung Tumors: Impact of Genetic, Clinical and Radiologic Advances Since the 2004 Classification. J Thorac Oncol 2015;10:1243-60.

7. Pelosi G, Barbareschi M, Cavazza A, et al. Large cell carcinoma of the lung: a tumor in search of an author. A clinically oriented critical reappraisal. Lung Cancer 2015;87:226-31.

8. Copin MC. Large cell carcinoma, lymphoepithelioma-like carcinoma, NUT carcinoma. Ann Pathol 2016;36:24-33.

9. Bi Y, Qu Y, Liang Z, et al. Clinicopathological analysis of Large Cell Lung Carcinomas definitely diagnosed according to the New World Health Organization Criteria. Pathol Res Pract 2018;214:555-9.

10. Weissferdt A. Large cell carcinoma of lung: On the verge of extinction? Semin Diagn Pathol 2014;31:278-88.

11. Lantuéjoul S, Brambilla E. What's new in the 2004 WHO classification of the lung tumors?. Rev Pneumol Clin 2008;64:187-94.

12. Sun YH, Lin SW, Hsieh CC, et al. Treatment outcomes of patients with different subtypes of large cell carcinoma of the lung. Ann Thorac Surg 2014;98:1013-9.

13. Hanagiri T, Oka S, Takenaka $S$, et al. Results of surgical resection for patients with large cell carcinoma of the lung. Int J Surg 2010;8:391-4.

14. Gálffy G. Diagnosis and treatment of the neuroendocrine tumors of the lung. Magy Onkol 2018;62:113-8.

15. Cao L, Li ZW, Wang M, et al. Clinicopathological characteristics, treatment and survival of pulmonary large cell neuroendocrine carcinoma: a SEER population-based study. Peer J 2019;7:e6539. 
16. Oshiro Y, Kusumoto M, Matsuno Y, et al. CT findings of surgically resected large cell neuroendocrine carcinoma of the lung in 38 patients. AJR Am J Roentgenol 2004;182:87-91.

17. Park MS, Shin DH, Chung KY, et al. Clinical features of bronchogenic large cell carcinoma confirmed by surgical resection. Korean J Intern Med 2003;18:212-9.

18. Iyoda A, Hiroshima K, Moriya Y, et al. Prospective study of adjuvant chemotherapy for pulmonary large cell neuroendocrine carcinoma. Ann Thorac Surg

Cite this article as: Tai Q, Zhang L, Hu X. Clinical characteristics and treatments of large cell lung carcinoma: a retrospective study using SEER data. Transl Cancer Res 2020;9(3):1455-1464. doi: 10.21037/tcr.2020.01.40
2006;82:1802-7.

19. Kujtan L, Muthukumar V, Kennedy KF, et al. The Role of Systemic Therapy in the Management of Stage I Large Cell Neuroendocrine Carcinoma of the Lung. J Thorac Oncol 2018;13:707-14.

20. Tiseo M, Bartolotti M, Gelsomino F, et al. First-line treatment in advanced non-small-cell lung cancer: the emerging role of the histologic subtype. Expert Rev Anticancer Ther 2009;9:425-35. 
Supplementary

Table S1 Characteristics of 488 patients after PSM analysis

\begin{tabular}{|c|c|c|c|}
\hline Characteristics & Non-chemotherapy $(n=244)$ & Chemotherapy $(n=244)$ & $P$ value \\
\hline Age & & & 1 \\
\hline$\leq 60$ & 69 & 69 & \\
\hline$>60$ & 175 & 175 & \\
\hline Gender & & & 1 \\
\hline Female & 98 & 98 & \\
\hline Male & 146 & 146 & \\
\hline Race & & & 1 \\
\hline White & 228 & 228 & \\
\hline Black & 11 & 11 & \\
\hline Other (American Indian/AK Native, Asian/Pacific Islander) & 5 & 5 & \\
\hline Marital Status & & & 1 \\
\hline Married & 175 & 175 & \\
\hline Single & 14 & 14 & \\
\hline Other (separated/divorced/widowed) & 55 & 55 & \\
\hline Primary site & & & 1 \\
\hline Main bronchus & 0 & 0 & \\
\hline Upper lobe, lung & 174 & 174 & \\
\hline Middle lobe, lung & 9 & 9 & \\
\hline Lower lobe, lung & 59 & 59 & \\
\hline Overlapping lesion & 1 & 1 & \\
\hline Lung, NOS & 1 & 1 & \\
\hline Laterality & & & 1 \\
\hline Left & 112 & 112 & \\
\hline Right & 132 & 132 & \\
\hline Bilateral & 0 & 0 & \\
\hline Grade & & & 1 \\
\hline Well + moderate & 0 & 0 & \\
\hline Poor + undifferentiated & 244 & 244 & \\
\hline Tumor size $(\mathrm{cm})$ & & & 1 \\
\hline$\leq 3$ & 83 & 83 & \\
\hline $3-5$ & 96 & 96 & \\
\hline $5-7$ & 37 & 37 & \\
\hline$\geq 7$ & 28 & 28 & \\
\hline Stage & & & 1 \\
\hline I & 80 & 80 & \\
\hline II & 95 & 95 & \\
\hline III & 55 & 55 & \\
\hline IV & 14 & 14 & \\
\hline
\end{tabular}

